\title{
In silico study on anti-Chikungunya virus activity of hesperetin
}

\author{
Adrian Oo $^{1}{ }^{\text {, }}$ Pouya Hassandarvish ${ }^{1}$, Sek Peng Chin ${ }^{2}$, Vannajan Sanghiran Lee ${ }^{2}$, Sazaly Abu Bakar ${ }^{1}$, Keivan \\ Zandi Corresp. 1 \\ ${ }^{1}$ Tropical Infectious Disease Research and Education Centre, Department of Medical Microbiology Faculty of Medicine, University of Malaya, Kuala \\ Lumpur, Malaysia \\ 2 Department of Chemistry, University of Malaya, Kuala Lumpur, Malaysia \\ Corresponding Author: Keivan Zandi \\ Email address: keivan@um.edu.my
}

Background. The re-emerging, Aedes spp. transmitted Chikungunya virus (CHIKV) has recently caused large outbreaks in a wide geographical distribution of the world including countries in Europe and America. Though fatalities associated with this self-remitting disease were rarely reported, quality of patients' lives have been severely diminished by polyarthralgia recurrence. Neither effective antiviral treatment nor vaccines are available for CHIKV. Our previousin vitroscreening showed that hesperetin, a bioflavonoid exhibits inhibitory effect on the virus intracellular replication. Here, we present a study using the computational approach to identify possible target proteins for future mechanistic studies of hesperetin.

Methods. 3D structures of CHIKV nsP2 (3TRK) and nsP3 (3GPG) were retrieved from Protein Data Bank (PDB), whereas nsP1, nsP4 and cellular factor SPK2 were modeled using Iterative Threading Assembly Refinement (I-TASSER) server based on respective amino acids sequence. We performed molecular docking on hesperetin against all four CHIKV non-structural proteins and SPK2. Proteins preparation and subsequent molecular docking were performed using Discovery Studio 2.5 and AutoDock Vina 1.5.6. The Lipinski's values of the ligand were computed and compared with the available data from PubChem. Two non-structural proteins with crystal structures 3GPG and 3TRK in complexed with hesperetin, demonstrated favorable free energy of binding from the docking study, were further explored using molecular dynamics (MD) simulations.

Results. We observed that hesperetin interacts with different types of proteins involving hydrogen bonds, pi-pi effects, pi-cation bonding and pi-sigma interactions with varying binding energies. Among all five tested proteins, our compound has the highest binding affinity with $3 G P G$ at $-8.5 \mathrm{kcal} / \mathrm{mol}$. The ligand used in this study also matches the Lipinski's rule of five in addition to exhibiting closely similar properties with that of in PubChem. The docking simulation was performed to obtain a first guess of the binding structure of hesperetin complex and subsequently analysed by MD simulations to assess the reliability of the docking results. Root mean square deviation (RMSD) of the simulated systems from MD simulations indicated that the hesperetin complex remains stable within the simulation timescale.

Discussion. The ligand's tendencies of binding to the important proteins for CHIKV replication were consistent with our previous in vitro screening which showed its efficacy in blocking the virus intracellular replication. NsP3 serves as the highest potential target protein for the compound's inhibitory effect, while it is interesting to highlight the possibility of interrupting CHIKV replication via interaction with host cellular factor. By complying the Lipinski's rule of five, hesperetin exhibits drug-like properties which projects its potential as a therapeutic option for CHIKV infection. 
1 In silico study on anti-Chikungunya virus activity of hesperetin

2

3 Adrian $\mathrm{Oo}^{1}$, Pouya Hassandarvish ${ }^{1}$, Chin Sek Peng ${ }^{2}$, Vannajan Sanghiran Lee ${ }^{2}$, Sazaly Abu

4 Bakar $^{1}$, Keivan Zandi ${ }^{1}$

5

$6 \quad{ }^{1}$ Tropical Infectious Disease Research and Education Centre, Department of Medical

7 Microbiology, Faculty of Medicine, University of Malaya, 50603 Kuala Lumpur, Malaysia.

$8 \quad{ }^{2}$ Department of Chemistry, Faculty of Science, University of Malaya, 50603 Kuala Lumpur,

9 Malaysia.

10

11 Corresponding author :

12 Keivan Zandi ${ }^{1}$

13

14

15

16

17

18

19 


\section{Abstract}

Background. The re-emerging, Aedes spp. transmitted Chikungunya virus (CHIKV) has recently caused large outbreaks in a wide geographical distribution of the world including countries in Europe and America. Though fatalities associated with this self-remitting disease were rarely reported, quality of patients' lives have been severely diminished by polyarthralgia recurrence. Neither effective antiviral treatment nor vaccines are available for CHIKV. Our previous in 31 vitro screening showed that hesperetin, a bioflavonoid exhibits inhibitory effect on the virus

32 intracellular replication. Here, we present a study using the computational approach to identify 33 possible target proteins for future mechanistic studies of hesperetin.

34 Methods. 3D structures of CHIKV nsP2 (3TRK) and nsP3 (3GPG) were retrieved from Protein Data Bank (PDB), whereas nsP1, nsP4 and cellular factor SPK2 were modeled using Iterative Threading Assembly Refinement (I-TASSER) server based on respective amino acids sequence.

37 We performed molecular docking on hesperetin against all four CHIKV non-structural proteins 38 and SPK2. Proteins preparation and subsequent molecular docking were performed using 39 Discovery Studio 2.5 and AutoDock Vina 1.5.6. The Lipinski's values of the ligand were 40 computed and compared with the available data from PubChem. Two non-structural proteins with 41 crystal structures 3GPG and 3TRK in complexed with hesperetin, demonstrated favorable free 42 energy of binding from the docking study, were further explored using molecular dynamics (MD) 43 simulations. 
44 Results. We observed that hesperetin interacts with different types of proteins involving hydrogen 45 bonds, pi-pi effects, pi-cation bonding and pi-sigma interactions with varying binding energies. 46 Among all five tested proteins, our compound has the highest binding affinity with $3 \mathrm{GPG}$ at -8.5

$47 \mathrm{kcal} / \mathrm{mol}$. The ligand used in this study also matches the Lipinski's rule of five in addition to 48 exhibiting closely similar properties with that of in PubChem. The docking simulation was 49 performed to obtain a first guess of the binding structure of hesperetin complex and subsequently 50 analysed by MD simulations to assess the reliability of the docking results. Root mean square 51 deviation (RMSD) of the simulated systems from MD simulations indicated that the hesperetin 52 complex remains stable within the simulation timescale.

53 Discussion. The ligand's tendencies of binding to the important proteins for CHIKV replication 54 were consistent with our previous in vitro screening which showed its efficacy in blocking the 55 virus intracellular replication. NsP3 serves as the highest potential target protein for the 56 compound's inhibitory effect, while it is interesting to highlight the possibility of interrupting

57 CHIKV replication via interaction with host cellular factor. By complying the Lipinski's rule of 58 five, hesperetin exhibits drug-like properties which projects its potential as a therapeutic option for 59 CHIKV infection. 


\section{Introduction}

70 Chikungunya virus (CHIKV) is an arthropod-borne virus classified under the arthritogenic group

71 of Alphavirus genus from the Togaviridae family (Assunção-Miranda et al. 2013). CHIKV is

72 primarily transmitted by female mosquitoes of the Aedes genus, namely Aedes aegypti and Aedes

73 albopictus, though Culex ethiopicus and Anopheles stephensi have also been reported as potential

74 vectors. Over the years, massive outbreaks have been recorded in Africa, India and Indian Ocean

75 islands as well as South and South-East Asia (Beesoon et al. 2008; Josseran et al. 2006; Lanciotti

76 et al. 2007). In addition to the spread of CHIKV by Aedes albopictus to America and Europe,

77 return of high viraemia infected travellers, have caused concerns of CHIKV transmittance to new

78 endemic regions (Angelini et al. 2007; Vega-Rúa et al. 2014). Within 2-4 days following the initial

79 mosquito bite, $\mathrm{CHIKV}$ enters the bloodstream where it disseminates to its respective target organs

80 for subsequent replication. Infected patients generally suffer from symptoms such as polythermia

$81\left(>39^{\circ} \mathrm{C}\right)$, maculopapular rashes, polyarthralgia, cephalgia and nauseas (Taubitz et al. 2007).

82 Further complications involving the inflammation of heart muscles (myocarditis), brain and

83 meninges (meningoencephalitis) as well as haemorrhage have also been reported but rare (Farnon

84 et al. 2008). Though CHIKV is a self-limiting viral infection, 30-40\% of patients have been

85 complaining of recurrent joint pains which may last from a few weeks up to several years following

86 recovery (Manimunda et al. 2010). 
87 This small, spherical and enveloped virus contains a single positive-strand RNA genome which is

88 about $11.8 \mathrm{~kb}$ in size (Presti et al. 2014). The genome is made up of two open reading frames

89 (ORFs), whereby the ORF covering 5' two-thirds of the genome codes for the non-structural

90 proteins, whereas CHIKV structural proteins are encoded by the 3' ORF (Snyder et al. 2013).

91 Cleavage of the polyproteins results in five structural (C, E3, E2, 6K, E1) and four nonstructural

92 (nsP1, nsP2, nsP3, nsP4) proteins, with distinct functions.

93 While the structural proteins are mainly involved in the early stages of CHIKV replication cycle

94 comprising of the attachment and entry of virus particles into infected cells, CHIKV nonstructural

95 proteins are vital for the intracellular replication of new virus particles. The nonstructural proteins

96 originated from a polyprotein (P1234) which is directly translated from the 5' two-thirds of

97 CHIKV genomic RNA. The section between nsP3 and nsP4 in the precursor protein is then cleaved

98 in cis, resulting in P123 and nsP4 proteins (Merits et al. 2001). Subsequently, an unstable

99 replication complex made up of these proteins as well as cellular factors is assembled, which

100 synthesizes minus-strand genomic RNA. Further cleavage of the P123 protein into nsP1 and P23,

101 together with nsP4, gives rise to a replication complex within virus-induced cytopathic vacuoles

102 (CPV I), capable of both the synthesis of sense and antisense genomic RNA (Froshauer et al. 1988;

103 Salonen et al. 2003; Shirako \& Strauss 1994). Following the complete processing into individual

$104 \mathrm{nsP} 1, \mathrm{nsP} 2, \mathrm{nsP} 3$ and nsP4 proteins, a stable polymerase complex is formed capable of the

105 production of the positive-sense genomic and subgenomic RNA molecules (Lemm et al. 1994).

106 The nsP1 protein via its guanine-7-methyltransferase and guanylyl transferase activities, catalyses

107 the capping and methylation of newly synthesized viral mRNA in addition to its role in the

108 synthesis of viral antisense RNA molecules (Ahola \& Kääriäinen 1995; Mi \& Stollar 1991). NsP1

109 is also involved in the attachment of virus polymerase complex to cellular membranes through 
110 interactions between the negatively-charged phospholipids with the amphipathic binding peptide

111 (BP), and is enhanced by nsP1 palmitoylation (Peränen et al. 1995). Study has shown that alteration

112 in the specific as well as the surrounding palmitoylation site reduces virus replication hence, its

113 viability (Ahola et al. 2000). The nsP2 is multifunctional whereby it possesses the $\mathrm{N}$-terminal RNA

114 triphosphatase domain which catalyses the capping of viral RNA as well as the protein's RNA

115 helicase activity (Fros et al. 2013; Karpe et al. 2011).

116 The C-terminal of the protein has cysteine protease activity which is essential for the autocatalysis

117 of the P123 polyprotein, as well as a domain with methyltransferase-like activity of undiscovered

118 function (Bouraï et al. 2012). It has also been reported that nsP2 regulates the transcription and

119 translation of viral proteins using the host cell machinery besides protection against interferon's

120 inhibitory activity (Fros et al. 2010). The nsP3 protein is made up of three domains, namely the

121 evolutionarily highly conserved N-terminus, the centre domain unique only for Alphaviruses and

122 the heavily phosphorylated C-terminus. Its macrodomain is suggested to mediate ADP-ribose 1"-

123 phosphate and/or other ADP-ribose derivatives metabolism which regulate cellular activities

124 (Seyedi et al. 2016). On the other hand, the Cterminus contains Src-homology 3 (SH3) binding

125 motifs for the localization of cellular amphiphysins Amph1 and BIN1/Amph2 following virus

126 infection which promote Alphavirus genome replication (Neuvonen et al. 2011). NsP3 also

127 mediates cellular stress response by blocking the assembly of stress granules via the interaction

128 between its SH3 binding motifs with Ras-GAP SH3 domain-binding protein (G3BP) (Fros et al.

129 2012). On the other hand, CHIKV nsP4 functions as RNA-dependent RNA polymerase vital for

130 the elongation of the newly synthesised viral RNA molecules (Rathore et al. 2013). A study also

131 demonstrated the close interactions between CHIKV nsP4 as well as nsP3 proteins with the heat

132 shock protein, HSP-90 which has been shown to play an important role in the replication process

133 of several DNA and RNA viruses (Rathore et al. 2014). 
134 Sphingosine kinases (SPKs) are lipid kinases involved in the conversion of sphingosine into

135 sphingosine-1-phosphate (S1P). Two types of SPKs are present in mammalian cells, namely SPK1

136 and SPK2 which are translated from SPHK1 gene on chromosome 17 and SPHK2 gene on

137 chromosome 19 respectively (Neubauer \& Pitson 2013). Previous studies have shown close

138 association between SPK/S1P pathway and important cellular processes such as cell growth,

139 inflammation and immune responses, with both types of SPKs having the opposing effects

140 (Maceyka et al. 2005; Okada et al. 2005; Olivera et al. 1999; Snider et al. 2010). Interestingly, in

141 addition to its contribution towards the development of degenerative diseases in humans, SPKs

142 also play important roles in several viral infections, including Dengue and Influenza A viruses for

143 SPK1 as well as Hepatitis C virus, Kaposi's sarcoma-associated herpes virus, and most importantly

144 for our study, CHIKV for SPK2 (Clarke et al. 2015; Couttas et al. 2014; Dai et al. 2014; Reid et

145 al. 2015; Seo et al. 2013; Yamane et al. 2014).

146 Flavonoids are a group of polyphenolic plant compounds which are synthesised via the

147 phenylpropanoid pathway. Over the years, different types of flavonoids have been the subject of

148 research for their wide range of medicinal benefits - anti-oxidant, anti-tumour, anti-inflammation

149 and anti-microbial activities (Martínez-Pérez et al. 2016; Paul Dzoyem et al. 2013; Procházková

150 et al. 2011; Serafini et al. 2010). Indeed, various flavonoids have been reported for their antiviral

151 properties against Dengue Virus (DENV), Herpes Simplex Virus

152 (HSV), Human Cytomegalovirus (HCMV) and etc (Cotin et al. 2012; Lyu et al. 2005; Moghaddam

153 et al. 2014; Ono et al. 1989; Zandi et al. 2011). In our previous study, we have found that hesperetin

154 which belongs to the flavanone class of flavonoids possesses effective inhibitory effect on the in

155 vitro intracellular replication of CHIKV (unpublished data). Hence, at present we will be

156 performing an in silico investigation to identify the possible target proteins for subsequent

157 mechanistic study of hesperetin on CHIKV. 


\section{Materials and Methods}

\section{Receptor and ligand preparation}

161 The receptors used in this study are the three-dimensional protein structures of CHIKV nsP1, nsP2,

$162 \mathrm{nsP} 3$, nsP4 and the mammalian cells' SPK2. CHIKV nsP1 and nsP4 as well as the SPK2 protein

163 structures were modelled using the Iterative Threading Assembly Refinement (ITASSER) server

164 based on the amino acid sequences obtained from Universal Protein Resource (UniProt) (Roy et

165 al. 2010; Yang et al. 2015; Zhang 2008). On the other hand, nsP2 and nsP3 crystal structures were

166 retrieved from the Protein Data Bank (PDB) with PDB IDs of 3TRK and 3GPG respectively. Using

167 the Discovery Studio 2.5 software, water molecules were removed and CHARMM27 force field

168 was applied onto these protein structures. Subequently, steric overlaps were removed and the

169 structures were processed 1000 steps using the smart-minimizer algorithm. Hesperetin was used

170 as the ligand in this experiment, of which the ligand structure was generated using ChemDraw

171 software (CambridgeSoft). The 2D-structure was then minimized using the Discovery Studio 2.5

172 software followed by the preparation of both the ligand and receptors during which hydrogen

173 molecules were added using the AutoDock Vina 1.5.6 software, which were then saved as PDBQT

174 files.

\section{Molecular Docking}

176 In our study, the binding properties of the ligand to each protein were analysed using the AutoDock

177 Vina 1.5.6 software. Blind dockings were performed in which grid boxes of sizes sufficient to

178 cover the entire receptors of interest were constructed according to the parameters as tabulated in

179 Table 1. All grid boxes were formed at spacing size of $1.000 \AA$. Following the docking procedure, 
180 the resulting PDBQT output file was first opened in the PyMOL software in which all protein

181 conformations were converged in a single file for further analysis. Each conformation was then

182 analysed using the AutoDock Vina 1.5.6 and Discovery Studio 2.5 software whereby information

183 such as binding affinities, interaction energies, van der Waals energies, electrostatic energies,

184 hydrogen bonding, pi-pi interactions, pi-cation interactions and close contacting residues were

185 obtained and recorded. Separately, the Lipinski's values for hesperetin were determined using the

186 Lipinski Filters (SCFBio, Delhi) (Jayaram et al. 2012; Lipinski 2004).

187 Molecular dynamics simulations

188

189 The docked complexes of hesperetin to the non-structural proteins - 3GPG and 3TRK which

190 demonstrated favourable free energy of binding during molecular docking were used as starting

191 structures for the molecular dynamics (MD) simulations. A total of $10 \mathrm{~ns}$ MD simulations were

192 performed using AMBER 14 (Case et al. 2010). Amber ff14SB force field (Maier et al. 2015) was

193 used to describe the proteins, waters and counter-ions. Antechamber was used to determine GAFF

194 atom types for hesperetin, following Amber standard protocol. Restrained ElectroStatic Potential

195 (RESP) charges were employed for ligands (Bayly et al. 1993). MD simulations were performed

196 using constant pressure (P) and temperature (T), NPT ensemble, maintaining the pressure and

197 temperature at $1.0 \mathrm{~atm}$ and $310 \mathrm{~K}$, respectively, by means of anisotropic pressure scaling and

198 Langevin dynamics. The periodic boundary conditions based on the particle mesh Ewald method

199 with a non-bonded cutoff of $8 \AA$ were used. The integration time step was set at 2 fs and the

200 SHAKE algorithm was used to constrain bond lengths involving hydrogen atoms. The system

201 simulated underwent two stages of minimization using steepest descent and conjugate gradient

202 with different parts of the system gradually released in stages. Then, it was slowly heated from 0

203 to $310 \mathrm{~K}$ within 500 ps with restraints on the complex. After the heating stage, the system was 
204 equilibrated for $1 \mathrm{~ns}$, followed by another $10 \mathrm{~ns}$ of a relaxed MD run. The complete system 205 trajectory was collected every 2 ps for analysis. Trajectories analyses were performed using the

206 CPPTRAJ modules (Roe \& Cheatham 2013) of AMBER 16. The relative binding free energy for 207 the complex was evaluated using MM-GBSA approach as implemented in Amber, using 208 MMPBSA.py module (Miller et al. 2012) in Amber 16. A total of 500 snapshots from the relax 209 MD trajectories were included in the calculations.

\section{Results}

212 In this study, hesperetin was screened for potential inhibitory activities against all four CHIKV's 213 non-structural proteins, namely nsP1, nsP2, nsP3 and nsP4 in addition to SPK2 via the docking of

214 the compound to each protein. Figures 1A-E show the bindings of hesperetin with the highest

215 binding affinities upon docking against the proteins of interest. As illustrated, hesperetin exhibits

216 the strongest binding affinity against $3 \mathrm{GPG}(-8.5 \mathrm{kcal} / \mathrm{mol})$, followed by nsP4 and SPK2 $(-7.7$

$217 \mathrm{kcal} / \mathrm{mol})$, nsP1 $(-7.6 \mathrm{kcal} / \mathrm{mol})$ and finally $3 \mathrm{TRK}(-6.9 \mathrm{kcal} / \mathrm{mol})$. The total interaction energies

218 between the ligand and proteins resulting from the electrostatic as well as the weaker van der Waals

219 forces are as tabulated in Table 2.

220 Besides looking into the binding affinities and energies involved in the interaction of hesperetin

221 with all five proteins, we have also taken into record of the bonds formed between the ligand and 222 the binding sites on each protein. For nsP1, hydrogen bonds observed between this ligand-receptor 223 proteins interactions are recorded in Table 3. Hesperetin exhibits pi-pi and pi-cation interactions 224 with TYR185, PHE43 and ARG70, ARG252, LYS442 respectively (Table 8). The Discovery 225 Studio 2.5 shows close amino acid residues found in the binding pocket between hesperetin and 
226 nsP1, namely LEU15, ALA17, LEU18, GLN19, ALA21, TYR22, ASN39, ALA40, PHE43,

227 ALA40, PRO68, ALA69, ARG70, ARG71 and ALA104 as displayed in Figure 2.

228 CHIKV's nsP2 is an important protein for the initial stage of new viral RNA synthesis. In this 229 study we carried out molecular docking of hesperetin on the cysteine protease domain of the virus $230 \mathrm{nsP} 2$, as denoted as 3TRK. The hydrogen bonds between hesperetin and 3TRK are as shown in

231 Table 4. Pi-effects are observed at tyrosine residues of TYR1079 and TYR1177 as well as the

232 phenylalanine PHE1225 (Table 8). In Figure 3, we have demonstrated the close residues of 3TRK

233 with hesperetin at ALA1046, TYR1047, SER1048, TYR1079, ASN1082, LEU1206, GLN1241 234 and GLY1245.

235 Another protein studied is the nsP3 protein as denoted 3GPG, which plays multiple roles in the 236 virus life cycle.. Table 5 documents the hydrogen bonds linking hesperetin and 3GPG obtained 237 from our docking experiment. Interestingly, we also observed pi-pi interactions with TRP148 and 238 TYR63, pi-cation interaction with LYS118 as well as pi-sigma with GLY30 and VAL113 (Table 239 8). Amino acid residues ALA22, ALA23, ASN24, ASP31, GLY32, VAL33, CYS34, PRO107, 240 LEU109, THR111, GLY112, VAL113, TYR114, CYS 143, ARG144 and ASP145 were also found 241 closely in the binding pocket with hesperetin (Figure 4).

242 We studied the potential inhibitory activity of hesperetin against CHIKV's nsP4 which serve as 243 the polymerase for the elongation of newly synthesised RNA strands by simulating the docking 244 process of the compound against this protein. In addition to the hydrogen bonds as shown in Table 245 6, most pi interactions formed in this ligand-protein pair are pi-cations at ARG374 and ARG70 246 (Table 8). The remaining pi-pi interactions formed at TYR22 and 
247 TYR185, whereas pi-sigma interaction was observed at ARG70 (Table 8). Illustrated in Figure 5

248 are the close residues including TRP199, ALA200, LEU313, CYS315, LYS316, Val321, VAL326,

249 PHE328, ASN363, ILE366, THR372, GLN373.

250 In addition to the virus proteins, we have also docked our compound of interest to cellular factor

251 vital for virus replication such as SPK2. Our work shows hydrogen bonds between hesperetin and

252 SPK2 as tabulated in Table 7. TYR372 and ARG351 interact with the ligand via pi-pi and pi-

253 cation bonding respectively (Table 8). The hesperetin-SPK2 interaction also saw amino acid

254 residues such as HIS251, ASN255, ASP259, CYS329, LEU425, PRO426, LEU427, PRO428,

255 LEU432, ALA433, GLU624, GLN625, VAL626, GLU627 and TYR628 in close vicinities within

256 the binding pocket (Figure 6).

257 In order to ensure that the designed hesperetin molecule used in this experiment possesses the

258 necessary drug-like properties to be developed as a therapeutic option for CHIKV infections, the

259 Lipinski's values of our compound were determined and compared with the available data in

260 PubChem (Table 9).

261 Hesperetin was found to bind and remain in the binding site throughout the simulation (see movie

262 files in Supplemental Files section). For both systems (3GPG and 3TRK), root mean square

263 deviation (RMSD) computed using the backbone atoms of the complex with respect to the

264 minimized starting structure was found to be less than $1.8 \AA$ (Figure 7). This showed that the

265 systems are well equilibrated and do not deviate greatly from their initial starting structure. The

266 lowest energy structures of the complexes are shown in Figure 8. To explore the binding of

267 hesperetin to $3 \mathrm{GPG}$ and $3 \mathrm{TRK}$, the relative free energy of binding was computed from enthalpy

268 contributions, using snapshots extracted from the trajectories, following the MM-GBSA approach

269 (Kollman et al. 2000; Srinivasan et al. 1998). Table 10 lists the contributions to the binding free 
270 energy for the simulated complexes - favourable contributions to the binding arose from van der

271 Waals interactions and the non-polar part of the solvation free energy, as opposed to unfavourable

272 total electrostatic contributions (EEL+EGB). The favourable binding free energy of -28.18 and -

$27317.46 \mathrm{kcal} / \mathrm{mol}$ were for 3GPG-hesperetin and 3TRK-hesperetin, respectively. The estimated

274 binding free energy calculated is in agreement with the docking study.

275

276 Discussion

277 Since the initial Tanzania outbreak in 1952, CHIKV epidemics have been recorded in several parts

278 of the world with different climate systems. The spread of CHIKV to countries outside the tropical

279 regions has been attributed to the single amino acid alteration from alanine to valine (A226V) in

280 the E1 gene (Tsetsarkin et al. 2007). To date, approved therapeutic options and vaccines for

281 CHIKV infections are lacking, though cases of CHIKV infected patients are constantly on the rise

282 globally. Mechanistic studies in the past have shown anti-CHIKV effect of several compounds as

283 a result of their interactions with different viral proteins, hence inhibiting further CHIKV

284 replication (Delogu et al. 2011; Kaur et al. 2013; Lani et al. 2015). Furthermore, computational

285 approaches have been applied by researchers in identifying potential interactions between drug 286 candidates with specific CHIKV proteins in an effort to discover a novel anti-Chikungunya

287 treatment (Agarwal et al. 2015; Nguyen et al. 2014; Singh et al. 2012). In this study, we aim to

288 investigate the potential inhibitory effects of hesperetin, a flavanone, on different CHIVK non-

289 structural proteins in addition to one of the cellular factors vital for CHIKV replication, SPK2.

290

291 Our findings showed that hesperetin possesses interactions with all four CHIKV non-structural

292 proteins as well as SPK2 at different binding affinities. This is consistent with the inhibitory 
293 efficacy of hesperetin during the virus intracellular replication observed during our previous in

294 vitro screening (unpublished data). Hesperetin has the highest tendency to bind with 3GPG

295 with the affinity of $-8.5 \mathrm{kcal} / \mathrm{mol}$, followed by both nsp 4 and SPK2 at $-7.7 \mathrm{kcal} / \mathrm{mol}$, nsP1 with

296 the binding strength of $-7.6 \mathrm{kcal} / \mathrm{mol}$ and finally 3 TRK bound at $-6.9 \mathrm{kcal} / \mathrm{mol}$. Hence,

297 CHIKV's nsP3 or 3GPG has the highest potential to be the target protein for hesperetin's

298 inhibitory activity on the virus intracellular replication, though other proteins under study

299 should not be excluded of the possibilities. Interestingly, CHIKV nsP3 protein plays a vital role

300 in the early stages of viral genome replication involving synthesis of viral negative-strand and

301 subgenomic RNAs (Lani et al. 2015). Previous study has also found that mutations resulting in

302 alteration of the protein's amphiphysin SH3 binding motif and downregulation of Amph2

303 expression have been found to diminish in vitro viral RNA replication (Neuvonen et al. 2011).

304 Inhibition of both the nsP3 and nsP4 proteins could also block CHIKV replication via the heat

305 shock protein, HSP-90 pathway (Rathore et al. 2014). Besides the virus polymerase nsP4 which

306 also modulate host immune response towards CHIKV infections via the PKR-like ER resident

307 kinase (PERK) pathway (Rathore et al. 2013), the host factor SPK2 was also ranked second by

308 the AutoDock Vina 1.5.6 based on their binding affinities. NsP3-mediated SPK2 re-localisation

309 to a puncta in the cytoplasm following an infection suggested the involvement of SPK2 in

310 CHIKV replication. Close association of SPK2 with host proteins for mRNA processing and

311 gene expression further link SPK2 with CHIKV replication process (Reid et al. 2015). Our

312 findings suggest that inhibitory effect of hesperetin could be contributed by both direct activity

313 on the virus proteins as well as cellular factors vital for the virus replication.

314

315 We have also identified the different types of non-covalent bonds between the ligand and the 316 receptor proteins, including the hydrogen bonds, pi-pi, pi-cation and pi-sigma interactions. 
317 Hydrogen bond is a dipole-dipole interaction involving the transfer of a proton from one

318 molecule to the electronegative recipient atom on another molecule. Hydrogen bond varies in

319 strength based on the distance of the hydrogen bond, whereby as described by Szatylowicz,

320 hydrogen bonds are classified as strong, moderate and weak if they fall into the ranges of $1.2 \AA$

$321-1.5 \AA, 1.5 \AA-2.2 \AA$ and $>2.2 \AA$ respectively (Szatyłowicz 2008). None of the hydrogen bonds

322 formed between hesperetin and all five proteins in this study fall under the strong category.

323 Instead, hesperetin formed moderately strong hydrogen bonds with relatively strong binding

324 affinities with ASP310, GLY311, ASP36, ARG71 and LEU135 of nsP1, TYR142, LEU108,

325 SER110, ARG144, GLU17, THR122 and ASN72 of 3GPG, GLN364, ALA104, ALA103,

326 ARG110, LEU135, ASP479 and THR437 of nsP4, and finally ARG373, GLN625 and ASP342

327 of SPK2. Though strong hydrogen bonds were also observed between hesperetin and 3TRK at

328 ASP1246 and TRP1084, their binding affinities were the lowest relative to the other four

329 proteins studied.

330 Another type of non-covalent interaction investigated in this experiment are the pi interactions,

331 which involve the electron-rich pi-system with another pi-system, anion, cation or other

332 molecules. Among all the pi-interactions investigated in this study, the pi-sigma bonds have the

333 strongest binding strength due to the larger overlaps of its s-orbitals (Harmony 1990; Sinanoglu

$334 \&$ Wiberg 1963). From our findings, we observed four pi-sigma interactions between hesperetin

335 and 3TRK at PHE1225, 3GPG at GLY30 and VAL113 as well as ARG70 of nsP4. We have

336 also documented the strong electrostatic forces between a polarised ligand and a receptor's

337 binding site, as well as the van der Waals interaction energies. Van der Waals interactions,

338 which are generally weaker as compared with the other forces, are formed when the cationic

339 nucleus of a molecule is attracted to the electron cloud of another molecule, or vice versa. It

340 results from transient alterations of polarisation in the nucleus affecting the surrounding dipole- 
341 dipole interactions and the nearby electron distribution. The weak van der Waals are

342 complemented with the presence of large numbers of bindings arising from good electrostatic

343 and steric interactions between both molecules (Copeland 2013).

344 The Lipinski's Rule of Five, also known as the Pfizer's Rule of Five by Christopher A. Lipinski

345 explains the basic criteria which one compound needs to possess to exhibit druglikeness properties.

346 Compounds which fulfil the following requirements are most likely to be membrane permeable

347 and have high bioavailability following oral administration - molecular weight less than 500

$348 \mathrm{~g} / \mathrm{mol}, \mathrm{Log} \mathrm{P}$ less than 5, less than $5 \mathrm{H}$-bond donors, less than $10 \mathrm{H}$-bond acceptors and molar

349 refractivity in the range of 40-130 (Lipinski et al. 2012). As shown in Table 9, the hesperetin

350 molecule used in our study matches all five of the Lipinski's Rule of Five - molecular weight of

$351302 \mathrm{~g} / \mathrm{mol}, \log \mathrm{P}$ of $2.5,3 \mathrm{H}$-bond donors, $6 \mathrm{H}$-bond acceptors and molar refractivity of 76.75.

352 We compared our findings with the available data from PubChem to ensure that the ligand

353 designed is reliable for our docking experiment. The results suggest that hesperetin has the

354 necessary properties to be developed into an effective oral therapeutic for CHIKV infections.

355 Furthermore, the non-structural proteins (3GPG and 3TRK) in complexed with hesperetin

356 remained stable throughout the $10 \mathrm{~ns}$ MD simulations. In all, these findings are of utmost

357 importance for determining whether hesperetin has the potential to be developed into an effective 358 antiviral drug against CHIKV infections as well as its highest possible target protein.

360 Conclusion

361 Hesperetin possesses interactions with all four CHIKV non-structural proteins in addition to SPK2

362 which plays a role in the virus replication cycle. These findings enhance our understandings on the 
363 possible underlying inhibitory mechanism of CHIKV replication, hence allowing further studies

364 on these target proteins for the development of novel anti-CHIKV drug.

365

366

367

368

369

370

371

372

373

374

375

376

377

378

379

380

381

382

383

384

385

386

387

388

389

390

391

392

393

394

395

396

397

398

399

400

401

402

403

404

\section{References}

Agarwal T, Asthana S, and Bissoyi A. 2015. Molecular modeling and docking study to elucidate novel chikungunya virus nsP2 protease inhibitors. Indian journal of pharmaceutical sciences 77:453.

Ahola T, and Kääriäinen L. 1995. Reaction in alphavirus mRNA capping: formation of a covalent complex of nonstructural protein nsP1 with 7-methyl-GMP. Proceedings of the National Academy of Sciences 92:507-511.

Ahola T, Kujala P, Tuittila M, Blom T, Laakkonen P, Hinkkanen A, and Auvinen P. 2000. Effects of palmitoylation of replicase protein nsP1 on alphavirus infection. Journal of virology 74:6725-6733.

Angelini R, Finarelli A, Angelini P, Po C, Petropulacos K, Macini P, Fiorentini C, Fortuna C, Venturi G, and Romi R. 2007. An outbreak of chikungunya fever in the province of Ravenna, Italy. Euro Surveill 12:E070906.

Assunção-Miranda I, Cruz-Oliveira C, and Da Poian AT. 2013. Molecular mechanisms involved in the pathogenesis of alphavirus-induced arthritis. BioMed research international 2013.

Bayly CI, Cieplak P, Cornell W, and Kollman PA. 1993. A well-behaved electrostatic potential based method using charge restraints for deriving atomic charges: the RESP model. The Journal of Physical Chemistry 97:10269-10280.

Beesoon S, Funkhouser E, Kotea N, Spielman A, and Robich RM. 2008. Chikungunya fever, Mauritius, 2006. Emerging infectious diseases 14:337.

Bouraï M, Lucas-Hourani M, Gad HH, Drosten C, Jacob Y, Tafforeau L, Cassonnet P, Jones LM, Judith D, and Couderc T. 2012. Mapping of Chikungunya virus interactions with host proteins identified nsP2 as a highly connected viral component. Journal of virology $86: 3121-3134$.

Case DA, Babin V, Berryman J, Betz RM, Cai Q, Cerutti DS, Cheatham III TE, Darden TA, Duke RE, Gohlke H, Goetz AW, Gusarov S, Homeyer N, Janowski P, Kaus J, Kolossváry I, Kovalenko A, Lee TS, LeGrand S, Luchko T, Luo R, Madej B, Merz KM, Paesani F, Roe DR, Roitberg A, Sagui C, Salomon-Ferrer R, Seabra G, Simmerling CL, Smith W, Swails J, Walker RC, Wang J, Wolf RM, Wu X, and Kollman PA. 2010. AMBER 14, University of California, San Francisco. 
405 Clarke JN, Davies LK, Calvert JK, Gliddon BL, Al Shujari WH, Aloia AL, Helbig KJ, Beard 406 MR, Pitson SM, and Carr JM. 2015. Reduction in sphingosine kinase 1 influences the susceptibility to dengue virus infection by altering anti-viral responses. Journal of General Virology.

Copeland RA. 2013. Evaluation of enzyme inhibitors in drug discovery: a guide for medicinal chemists and pharmacologists: John Wiley \& Sons.

Cotin S, Calliste C-A, Mazeron M-C, Hantz S, Duroux J-L, Rawlinson WD, Ploy M-C, and Alain S. 2012. Eight flavonoids and their potential as inhibitors of human cytomegalovirus replication. Antiviral research 96:181-186.

Couttas TA, Kain N, Daniels B, Lim XY, Shepherd C, Kril J, Pickford R, Li H, Garner B, and Don AS. 2014. Loss of the neuroprotective factor Sphingosine 1-phosphate early in Alzheimer's disease pathogenesis. Acta neuropathologica communications 2:1.

Dai L, Plaisance-Bonstaff K, Voelkel-Johnson C, Smith CD, Ogretmen B, Qin Z, and Parsons C. 2014. Sphingosine kinase-2 maintains viral latency and survival for KSHV-infected endothelial cells. PloS one 9.

Delogu I, Pastorino B, Baronti C, Nougairède A, Bonnet E, and de Lamballerie X. 2011. In vitro antiviral activity of arbidol against Chikungunya virus and characteristics of a selected resistant mutant. Antiviral research 90:99-107.

Farnon EC, Sejvar JJ, and Staples JE. 2008. Severe disease manifestations associated with acute chikungunya virus infection*. Critical care medicine 36:2682-2683.

Fros JJ, Domeradzka NE, Baggen J, Geertsema C, Flipse J, Vlak JM, and Pijlman GP. 2012. Chikungunya virus nsP3 blocks stress granule assembly by recruitment of G3BP into cytoplasmic foci. Journal of virology 86:10873-10879.

Fros JJ, Liu WJ, Prow NA, Geertsema C, Ligtenberg M, Vanlandingham DL, Schnettler E, Vlak JM, Suhrbier A, and Khromykh AA. 2010. Chikungunya virus nonstructural protein 2 inhibits type I/II interferon-stimulated JAK-STAT signaling. Journal of virology 84:10877-10887.

Fros JJ, van der Maten E, Vlak JM, and Pijlman GP. 2013. The C-terminal domain of chikungunya virus nsP2 independently governs viral RNA replication, cytopathicity, and inhibition of interferon signaling. Journal of virology 87:10394-10400.

Froshauer S, Kartenbeck J, and Helenius A. 1988. Alphavirus RNA replicase is located on the cytoplasmic surface of endosomes and lysosomes. The Journal of cell biology 107:20752086. 
450

451

452

453

454

455

456

457

458

459

460

461

462

463

464

465

466

467

468

469

470

471

472

473

474

475

476

477

478

479

480

481

482

483

484

485

486

487

488

489

490

491

492
449 Harmony MD. 1990. The equilibrium carbon-carbon single-bond length in ethane. The Journal of chemical physics 93:7522-7523.

Jayaram B, Singh T, Mukherjee G, Mathur A, Shekhar S, and Shekhar V. 2012. Sanjeevini: a freely accessible web-server for target directed lead molecule discovery. BMC bioinformatics 13:S7.

Josseran L, Paquet C, Zehgnoun A, Caillere N, Le Tertre A, Solet J-L, and Ledrans M. 2006. Chikungunya disease outbreak, Reunion island. Emerging infectious diseases 12:1994.

Karpe YA, Aher PP, and Lole KS. 2011. NTPase and 5'-RNA triphosphatase activities of Chikungunya virus nsP2 protein. PloS one 6:e22336.

Kaur P, Thiruchelvan M, Lee RCH, Chen H, Chen KC, Ng ML, and Chu JJH. 2013. Inhibition of chikungunya virus replication by harringtonine, a novel antiviral that suppresses viral protein expression. Antimicrobial agents and chemotherapy 57:155167.

Kollman PA, Massova I, Reyes C, Kuhn B, Huo S, Chong L, Lee M, Lee T, Duan Y, Wang W, Donini O, Cieplak P, Srinivasan J, Case DA, and Cheatham TE. 2000. Calculating structures and free energies of complex molecules: combining molecular mechanics and continuum models. Accounts of chemical research 33:889-897.

Lanciotti RS, Kosoy OL, Laven JJ, Panella AJ, Velez JO, Lambert AJ, and Campbell GL. 2007. Chikungunya virus in US travelers returning from India, 2006. Emerging infectious diseases 13:764.

Lani R, Hassandarvish P, Chiam CW, Moghaddam E, Chu JJH, Rausalu K, Merits A, Higgs S, Vanlandingham D, and Bakar SA. 2015. Antiviral activity of silymarin against chikungunya virus. Scientific reports 5.

Lemm JA, Rümenapf T, Strauss EG, Strauss JH, and Rice C. 1994. Polypeptide requirements for assembly of functional Sindbis virus replication complexes: a model for the temporal regulation of minus-and plus-strand RNA synthesis. The EMBO journal 13:2925.

Lipinski CA. 2004. Lead-and drug-like compounds: the rule-of-five revolution. Drug Discovery Today: Technologies 1:337-341.

Lipinski CA, Lombardo F, Dominy BW, and Feeney PJ. 2012. Experimental and computational approaches to estimate solubility and permeability in drug discovery and development settings. Advanced drug delivery reviews 64:4-17.

Lyu S-Y, Rhim J-Y, and Park W-B. 2005. Antiherpetic activities of flavonoids against herpes simplex virus type 1 (HSV-1) and type 2 (HSV-2) in vitro. Archives of pharmacal research 28:1293-1301. 
493

494

495

496

497

498

499

500

501

502

503

504

505

506

507

508

509

510

511

512

513

514

515

516

517

518

519

520

521

522

523

524

525

526

527

528

529

530

531

532

533

534

535

536

Maceyka M, Sankala H, Hait NC, Le Stunff H, Liu H, Toman R, Collier C, Zhang M, Satin LS, and Merrill AH. 2005. SphK1 and SphK2, sphingosine kinase isoenzymes with opposing functions in sphingolipid metabolism. Journal of Biological Chemistry 280:37118-37129.

Maier JA, Martinez C, Kasavajhala K, Wickstrom L, Hauser KE, and Simmerling C. 2015. ff14SB: Improving the Accuracy of Protein Side Chain and Backbone Parameters from ff99SB. J Chem Theory Comput 11:3696-3713. 10.1021/acs.jctc.5b00255

Manimunda SP, Vijayachari P, Uppoor R, Sugunan AP, Singh SS, Rai SK, Sudeep AB, Muruganandam N, Chaitanya IK, and Guruprasad DR. 2010. Clinical progression of chikungunya fever during acute and chronic arthritic stages and the changes in joint morphology as revealed by imaging. Transactions of the Royal Society of Tropical Medicine and Hygiene 104:392-399.

Martínez-Pérez C, Ward C, Turnbull AK, Mullen P, Cook G, Meehan J, Jarman EJ, Thomson PI, Campbell CJ, and McPhail D. 2016. Antitumour activity of the novel flavonoid Oncamex in preclinical breast cancer models. British Journal of Cancer 114:905-916.

Merits A, Vasiljeva L, Ahola T, Kääriäinen L, and Auvinen P. 2001. Proteolytic processing of Semliki Forest virus-specific non-structural polyprotein by nsP2 protease. Journal of General Virology 82:765-773.

Mi S, and Stollar V. 1991. Expression of Sindbis virus nsP1 and methyltransferase activity inEscherichia coli. Virology 184:423-427.

Miller BR, McGee TD, Swails JM, Homeyer N, Gohlke H, and Roitberg AE. 2012. MMPBSA.py: An Efficient Program for End-State Free Energy Calculations. Journal of Chemical Theory and Computation 8:3314-3321. 10.1021/ct300418h

Moghaddam E, Teoh B-T, Sam S-S, Lani R, Hassandarvish P, Chik Z, Yueh A, Abubakar S, and Zandi K. 2014. Baicalin, a metabolite of baicalein with antiviral activity against dengue virus. Scientific reports 4.

Neubauer HA, and Pitson SM. 2013. Roles, regulation and inhibitors of sphingosine kinase 2. FEBS Journal 280:5317-5336.

Neuvonen M, Kazlauskas A, Martikainen M, Hinkkanen A, Ahola T, and Saksela K. 2011. SH3 domain-mediated recruitment of host cell amphiphysins by alphavirus nsP3 promotes viral RNA replication. PLoS Pathog 7:e1002383.

Nguyen PT, Yu H, and Keller PA. 2014. Discovery of in silico hits targeting the nsP3 macro domain of chikungunya virus. Journal of Molecular modeling 20:1-12.

PeerJ reviewing PDF | (2016:05:10977:1:1:NEW 23 Sep 2016) 
537 Okada T, Ding G, Sonoda H, Kajimoto T, Haga Y, Khosrowbeygi A, Gao S, Miwa N, Jahangeer $538 \quad \mathrm{~S}$, and Nakamura S-i. 2005. Involvement of N-terminal-extended form of sphingosine 539 kinase 2 in serum-dependent regulation of cell proliferation and apoptosis. Journal of Biological Chemistry 280:36318-36325.

Olivera A, Kohama T, Edsall L, Nava V, Cuvillier O, Poulton S, and Spiegel S. 1999. Sphingosine kinase expression increases intracellular sphingosine-1-phosphate and promotes cell growth and survival. The Journal of cell biology 147:545-558.

Ono K, Nakane H, Fukushima M, Chermann J-C, and Barré-Sinoussi F. 1989. Inhibition of reverse transcriptase activity by a flavonoid compound, 5, 6, 7-trihydroxyflavone. Biochemical and biophysical research communications 160:982-987.

Paul Dzoyem J, Hamamoto H, Ngameni B, Tchaleu Ngadjui B, and Sekimizu K. 2013. Antimicrobial action mechanism of flavonoids from Dorstenia species. Drug discoveries \& therapeutics 7:66-72.

Peränen J, Laakkonen P, Hyvönen M, and Kääriäinen L. 1995. The alphavirus replicase protein nsP1 is membrane-associated and has affinity to endocytic organelles. Virology 208:610620.

Presti AL, Lai A, Cella E, Zehender G, and Ciccozzi M. 2014. Chikungunya virus, epidemiology, clinics and phylogenesis: A review. Asian Pacific journal of tropical medicine 7:925-932.

Procházková D, Boušová I, and Wilhelmová N. 2011. Antioxidant and prooxidant properties of flavonoids. Fitoterapia 82:513-523.

Rathore AP, Haystead T, Das PK, Merits A, Ng M-L, and Vasudevan SG. 2014. Chikungunya virus nsP3 \& nsP4 interacts with HSP-90 to promote virus replication: HSP-90 inhibitors reduce CHIKV infection and inflammation in vivo. Antiviral research 103:7-16.

Rathore AP, Ng M-L, and Vasudevan SG. 2013. Differential unfolded protein response during Chikungunya and Sindbis virus infection: CHIKV nsP4 suppresses eIF2 $\alpha$ phosphorylation. Virology journal 10:1.

Reid SP, Tritsch SR, Kota K, Chiang C-Y, Dong L, Kenny T, Brueggemann EE, Ward MD, Cazares LH, and Bavari S. 2015. Sphingosine kinase 2 is a chikungunya virus host factor co-localized with the viral replication complex. Emerging microbes \& infections $4: \mathrm{e} 61$.

Roe DR, and Cheatham TE. 2013. PTRAJ and CPPTRAJ: Software for Processing and Analysis of Molecular Dynamics Trajectory Data. Journal of Chemical Theory and Computation 9:3084-3095. 10.1021/ct400341p 
582 Roy A, Kucukural A, and Zhang Y. 2010. I-TASSER: a unified platform for automated protein

583

584

585

586

587

588

589

590

591

592

593

594

595

596

597

598

599

600

601

602

603

604

605

606

607

608

609

610

611

612

613

614

615

616

617

618

619

620

621

622

623

624

625 structure and function prediction. Nature protocols 5:725-738.

Salonen A, Vasiljeva L, Merits A, Magden J, Jokitalo E, and Kääriäinen L. 2003. Properly folded nonstructural polyprotein directs the Semliki Forest virus replication complex to the endosomal compartment. Journal of virology 77:1691-1702.

Seo Y-J, Pritzl CJ, Vijayan M, Bomb K, McClain ME, Alexander S, and Hahm B. 2013. Sphingosine kinase 1 serves as a pro-viral factor by regulating viral RNA synthesis and nuclear export of viral ribonucleoprotein complex upon influenza virus infection. PloS one 8:e75005.

Serafini M, Peluso I, and Raguzzini A. 2010. Flavonoids as anti-inflammatory agents. Proceedings of the Nutrition Society 69:273-278.

Seyedi SS, Shukri M, Hassandarvish P, Oo A, Muthu SE, Abubakar S, and Zandi K. 2016. Computational Approach Towards Exploring Potential Anti-Chikungunya Activity of Selected Flavonoids. Scientific reports 6.

Shirako Y, and Strauss JH. 1994. Regulation of Sindbis virus RNA replication: uncleaved P123 and nsP4 function in minus-strand RNA synthesis, whereas cleaved products from P123 are required for efficient plus-strand RNA synthesis. Journal of virology 68:1874-1885.

Sinanoglu O, and Wiberg KB. 1963. Sigma molecular orbital theory. Chem Phys 39:20.

Singh KD, Kirubakaran P, Nagarajan S, Sakkiah S, Muthusamy K, Velmurgan D, and Jeyakanthan J. 2012. Homology modeling, molecular dynamics, e-pharmacophore mapping and docking study of Chikungunya virus nsP2 protease. Journal of Molecular modeling 18:39-51.

Snider AJ, Gandy KAO, and Obeid LM. 2010. Sphingosine kinase: role in regulation of bioactive sphingolipid mediators in inflammation. Biochimie 92:707-715.

Snyder JE, Kulcsar KA, Schultz KL, Riley CP, Neary JT, Marr S, Jose J, Griffin DE, and Kuhn RJ. 2013. Functional characterization of the alphavirus TF protein. Journal of virology $87: 8511-8523$.

Srinivasan J, Cheatham TE, Cieplak P, Kollman PA, and Case DA. 1998. Continuum Solvent Studies of the Stability of DNA, RNA, and Phosphoramidate-DNA Helices. Journal of the American Chemical Society 120:9401-9409. 10.1021/ja981844+

Szatyłowicz H. 2008. Structural aspects of the intermolecular hydrogen bond strength: Hbonded complexes of aniline, phenol and pyridine derivatives. Journal of Physical Organic Chemistry 21:897-914. 
626

627

628

629

630

631

632

633

634

635

636

637

638

639

640

641

642

643

644

645

646

647

648

649

650

651
Taubitz W, Cramer JP, Kapaun A, Pfeffer M, Drosten C, Dobler G, Burchard GD, and Löscher T. 2007. Chikungunya fever in travelers: clinical presentation and course. Clinical infectious diseases 45:e1-e4.

Tsetsarkin KA, Vanlandingham DL, McGee CE, and Higgs S. 2007. A single mutation in chikungunya virus affects vector specificity and epidemic potential. PLoS pathogens 3:e201.

Vega-Rúa A, Zouache K, Girod R, Failloux A-B, and Lourenço-de-Oliveira R. 2014. High level of vector competence of Aedes aegypti and Aedes albopictus from ten American countries as a crucial factor in the spread of Chikungunya virus. Journal of virology 88:6294-6306.

Yamane D, McGivern DR, Wauthier E, Yi M, Madden VJ, Welsch C, Antes I, Wen Y, Chugh PE, and McGee CE. 2014. Regulation of the hepatitis C virus RNA replicase by endogenous lipid peroxidation. Nature medicine 20:927-935.

Yang J, Yan R, Roy A, Xu D, Poisson J, and Zhang Y. 2015. The I-TASSER Suite: protein structure and function prediction. Nature methods 12:7-8.

Zandi K, Teoh B-T, Sam S-S, Wong P-F, Mustafa MR, and AbuBakar S. 2011. Antiviral activity of four types of bioflavonoid against dengue virus type-2. Virology journal 8:1.

Zhang Y. 2008. I-TASSER server for protein 3D structure prediction. BMC bioinformatics 9:40. 


\section{Table $\mathbf{1}$ (on next page)}

Parameters used for molecular docking of hesperetin with each protein of interest.

All grid boxes with spacing size of $1.000 \AA$ have sufficient sizes to cover the entire protein structures during molecular docking. 


\begin{tabular}{ccccccc}
\hline Proteins & Center-X & Center-Y & Center-Z & Size-X & Size-Y & Size-Z \\
\hline Nsp1 & 8.490 & -21.201 & -6.330 & 96 & 78 & 70 \\
\hline 3TRK & 11.569 & 24.420 & 21.707 & 52 & 76 & 56 \\
\hline 3GPG & 8.490 & -21.201 & -21.201 & 96 & 78 & 70 \\
\hline NsP4 & 76.026 & 77.432 & 77.204 & 78 & 84 & 58 \\
\hline SPK2 & 67.704 & 77.970 & 71.232 & 72 & 72 & 68 \\
\hline
\end{tabular}

1 


\section{Table 2 (on next page)}

Binding energies between hesperetin and different types of proteins.

The energies involved in each ligand-receptor interaction was analysed using the Discovery Studio 2.5 . 


\begin{tabular}{cccc}
\hline Proteins & $\begin{array}{c}\text { Electrostatic } \\
\text { Interaction Energy } \\
(\mathbf{k c a l} / \mathbf{m o l})\end{array}$ & $\begin{array}{c}\text { Van der Waals } \\
\text { Interaction Energy } \\
(\mathbf{k c a l} / \mathbf{m o l})\end{array}$ & $\begin{array}{c}\text { Interaction Energy } \\
(\mathbf{k c a l} / \mathbf{m o l})\end{array}$ \\
\hline NsP1 & 16.785 & -29.699 & -12.914 \\
3TRK & -454.598 & -83.186 & -537.784 \\
3GPG & -405.273 & -129.780 & -535.053 \\
NSP4 & -32.689 & -28.904 & -61.594 \\
SPK2 & 14.815 & -27.477 & -12.663 \\
\hline
\end{tabular}

1 


\section{Table 3(on next page)}

Hydrogen bonding between hesperetin and CHIKV nsP1.

This table documents the residues involved in the hydrogen bond formation as well as the angle DHA and length of the hydrogen bonds as analysed using the Discovery Studio 2.5. The binding affinities as ranked by the AutoDock Vina 1.5.6 are recorded in the final column of the table. 


\begin{tabular}{|c|c|c|c|}
\hline Hydrogen bonds & Angle DHA $\left(^{\circ}\right)$ & Distance $(\AA)$ & $\begin{array}{c}\text { Binding Affinity } \\
\text { (kcal/mol) }\end{array}$ \\
\hline $\begin{array}{c}\text { Hesperetin:UNK1:H2 - } \\
\text { nsP1:ASP310:OD1 }\end{array}$ & $167.07^{\circ}$ & 1.66709 & \multirow{5}{*}{-7.6} \\
\hline $\begin{array}{c}\text { nsP1:GLY311:HN - } \\
\text { Hesperetin:UNK1:O19 }\end{array}$ & $159.57^{\circ}$ & 2.13746 & \\
\hline $\begin{array}{l}\text { nsP1:ARG365:HH21 - } \\
\text { Hesperetin:UNK1:O20 }\end{array}$ & $93.9791^{\circ}$ & 2.49524 & \\
\hline $\begin{array}{l}\text { nsP1:ARG365:HH22 - } \\
\text { Hesperetin:UNK1:O20 }\end{array}$ & $104.508^{\circ}$ & 2.33411 & \\
\hline $\begin{array}{l}\text { nsP1:ARG365:HH22 - } \\
\text { Hesperetin:UNK1:O21 }\end{array}$ & $121.423^{\circ}$ & 2.29742 & \\
\hline $\begin{array}{l}\text { Hesperetin:UNK1:H1 - } \\
\text { nsP1:HIS45:ND1 }\end{array}$ & $149.472^{\circ}$ & 2.28058 & \multirow{2}{*}{-7.5} \\
\hline $\begin{array}{c}\text { nsP1:GLY190:HN - } \\
\text { Hesperetin:UNK1:O20 }\end{array}$ & $124.29^{\circ}$ & 2.43961 & \\
\hline $\begin{array}{c}\text { Hesperetin:UNK1:H1 - } \\
\text { nsP1:ASP36:OD2 }\end{array}$ & $125.798^{\circ}$ & 2.08242 & \multirow{6}{*}{-7.4} \\
\hline $\begin{array}{c}\text { Hesperetin:UNK1:H2 - } \\
\text { nsP1:PRO68:O }\end{array}$ & $146.956^{\circ}$ & 2.24366 & \\
\hline $\begin{array}{c}\text { nsP1:ARG71:HH11 - } \\
\text { Hesperetin:UNK1:O20 }\end{array}$ & $158.052^{\circ}$ & 2.07172 & \\
\hline $\begin{array}{c}\text { Hesperetin:UNK1:H3 - } \\
\text { nsP1:GLU129:O }\end{array}$ & $119.206^{\circ}$ & 2.47249 & \\
\hline $\begin{array}{c}\text { nsP1:LEU108:HN - } \\
\text { Hesperetin:UNK1:O20 }\end{array}$ & $153.395^{\circ}$ & 2.33121 & \\
\hline $\begin{array}{c}\text { nsP1:LEU135:HN - } \\
\text { Hesperetin:UNK1:O17 }\end{array}$ & $125.791^{\circ}$ & 2.08609 & \\
\hline $\begin{array}{c}\text { nsP1:ARG70:HN - } \\
\text { Hesperetin:UNK1:O17 }\end{array}$ & $134.179^{\circ}$ & 2.09364 & \multirow{2}{*}{-7.3} \\
\hline $\begin{array}{l}\text { nsP1:ARG252:HH12 - } \\
\text { Hesperetin:UNK1:O20 }\end{array}$ & $171.884^{\circ}$ & 2.30037 & \\
\hline $\begin{array}{c}\text { Hesperetin:UNK1:H1 - } \\
\text { nsP1:ASP448:OD1 }\end{array}$ & $154.403^{\circ}$ & 1.82012 & \multirow{2}{*}{-7.2} \\
\hline $\begin{array}{c}\text { Hesperetin:UNK1:H3 - } \\
\text { nsP1:VAL475:O }\end{array}$ & $159.829^{\circ}$ & 1.84851 & \\
\hline $\begin{array}{c}\text { Hesperetin:UNK1:H3 - } \\
\text { nsP1:SER44:OG }\end{array}$ & $119.912^{\circ}$ & 2.48095 & \multirow{2}{*}{-6.9} \\
\hline $\begin{array}{l}\text { nsP1:ARG71:HH12 - } \\
\text { Hesperetin:UNK1:O20 }\end{array}$ & $126.228^{\circ}$ & 2.28728 & \\
\hline
\end{tabular}




\section{Table 4 (on next page)}

Hydrogen bonding between hesperetin and 3TRK.

This table documents the residues involved in the hydrogen bond formation as well as the angle DHA and length of the hydrogen bonds as analysed using the Discovery Studio 2.5. The binding affinities as ranked by the AutoDock Vina 1.5.6 are recorded in the final column of the table. 


\begin{tabular}{|c|c|c|c|}
\hline Hydrogen bonds & Angle DHA $\left(^{\circ}\right)$ & Distance $(\AA)$ & $\begin{array}{c}\text { Binding Affinity } \\
\text { (kcal/mol) }\end{array}$ \\
\hline $\begin{array}{c}\text { Hesperetin:UNK1:H3 - } \\
\text { 3TRK:ASP1246:OD1 }\end{array}$ & 132.214 & 2.19274 & \multirow{3}{*}{-6.9} \\
\hline $\begin{array}{l}\text { 3TRK:TRP1084:HE1 - } \\
\text { Hesperetin:UNK1:O18 }\end{array}$ & 140.389 & 2.20564 & \\
\hline $\begin{array}{l}\text { 3TRK:TRP1084:HE1 - } \\
\text { Hesperetin:UNK1:O19 }\end{array}$ & 148.713 & 2.13609 & \\
\hline $\begin{array}{c}\text { Hesperetin:UNK1:H3 - } \\
\text { 3TRK:Ser1048:OG }\end{array}$ & 144.592 & 2.32087 & -6.8 \\
\hline $\begin{array}{c}\text { Hesperetin:UNK1:H1 - } \\
\text { 3TRK:GLN1241:O }\end{array}$ & 93.425 & 2.48789 & -6.6 \\
\hline $\begin{array}{l}\text { 3TRK:ALA1180:HN - } \\
\text { Hesperetin:UNK1:O20 }\end{array}$ & 136.259 & 2.09817 & -6.5 \\
\hline $\begin{array}{l}\text { 3TRK:LYS1091:HZ2 - } \\
\text { Hesperetin:UNK1:O18 }\end{array}$ & 134.881 & 2.44139 & \multirow{4}{*}{-6.4} \\
\hline $\begin{array}{c}\text { 3TRK:ARG1267:HH12 - } \\
\text { Hesperetin:UNK1:O19 }\end{array}$ & 141.467 & 2.27262 & \\
\hline $\begin{array}{c}\text { 3TRK:ARG1267:HH22 - } \\
\text { Hesperetin:UNK1:O19 }\end{array}$ & 149.413 & 2.06422 & \\
\hline $\begin{array}{c}\text { Hesperetin:UNK1:H1 - } \\
\text { 3TRK:LEU1065:O }\end{array}$ & 144.638 & 2.23416 & \\
\hline $\begin{array}{l}\text { 3TRK:PHE1225:HN - } \\
\text { Hesperetin:UNK1:O10 }\end{array}$ & 145.498 & 2.33505 & \multirow{3}{*}{-6.1} \\
\hline $\begin{array}{l}\text { 3TRK:ASN1135:HN - } \\
\text { Hesperetin:UNK1:O18 }\end{array}$ & 126.233 & 2.487381 & \\
\hline $\begin{array}{l}\text { 3TRK:ASN1135:HN - } \\
\text { Hesperetin:UNK1:O19 }\end{array}$ & 129.610 & 2.38619 & \\
\hline
\end{tabular}




\section{Table 5 (on next page)}

Hydrogen bonding between hesperetin and 3GPG.

This table documents the residues involved in the hydrogen bond formation as well as the angle DHA and length of the hydrogen bonds as analysed using the Discovery Studio 2.5. The binding affinities as ranked by the AutoDock Vina 1.5.6 are recorded in the final column of the table. 


\begin{tabular}{|c|c|c|c|}
\hline Hydrogen bonds & Angle DHA $\left(^{\circ}\right)$ & Distance $(\AA)$ & $\begin{array}{l}\text { Binding Affinity } \\
\text { (kcal/mol) }\end{array}$ \\
\hline $\begin{array}{c}\text { Hesperetin:UNK1:H1 - } \\
\text { 3GPG:TYR142:O }\end{array}$ & 123.476 & 1.97816 & \multirow{3}{*}{-8.5} \\
\hline $\begin{array}{c}\text { 3GPG:LEU108:HN - } \\
\text { Hesperetin:UNK1:O17 }\end{array}$ & 162.843 & 2.17416 & \\
\hline $\begin{array}{c}\text { 3GPG:SER110:HN - } \\
\text { Hesperetin:UNK1:O20 }\end{array}$ & 145.746 & 2.0736 & \\
\hline $\begin{array}{c}\text { 3GPG:VAL33:HN - } \\
\text { Hesperetin:UNK1:O20 }\end{array}$ & 125.205 & 2.35031 & \multirow{2}{*}{-8.3} \\
\hline $\begin{array}{l}\text { 3GPG:ARG144:HN - } \\
\text { Hesperetin:UNK1:O19 }\end{array}$ & 159.099 & 1.95421 & \\
\hline $\begin{array}{c}\text { Hesperetin:UNK1:H2 - } \\
\text { 3GPG:GLU17:O }\end{array}$ & 165.815 & 1.93615 & \multirow{3}{*}{-7.3} \\
\hline $\begin{array}{l}\text { 3GPG:THR122:HN - } \\
\text { Hesperetin:UNK1:O }\end{array}$ & 145.209 & 2.13631 & \\
\hline $\begin{array}{l}\text { 3GPG:ASN72:HD22 - } \\
\text { Hesperetin:UNK1:O20 }\end{array}$ & 139.167 & 2.03974 & \\
\hline $\begin{array}{l}\text { 3GPG:SER110:HN - } \\
\text { Hepseretin:UNK1:O21 }\end{array}$ & 152.590 & 1.95709 & \multirow{3}{*}{-7.0} \\
\hline $\begin{array}{c}\text { 3GPG:TRP41:HE1 - } \\
\text { Hesperetin:UNK1:O18 }\end{array}$ & 123.985 & 2.27795 & \\
\hline $\begin{array}{c}\text { 3GPG:LYS7:HZ2 - } \\
\text { Hesperetin:UNK1:O20 }\end{array}$ & 144.885 & 2.15643 & \\
\hline $\begin{array}{c}\text { Hesperetin:UNK1:H3 - } \\
\text { 3GPG:TYR4:O }\end{array}$ & 148.477 & 2.16364 & \multirow{6}{*}{-6.9} \\
\hline $\begin{array}{l}\text { 3GPG:GLN157:HE22 - } \\
\text { Hesperetin:UNK1:O20 }\end{array}$ & 129.097 & 2.30335 & \\
\hline $\begin{array}{l}\text { Hesperetin:UNK1:H1 - } \\
\text { 3GPG:GLY116:O }\end{array}$ & 128.866 & 2.03758 & \\
\hline $\begin{array}{c}\text { Hesperetin:UNK1:H2 - } \\
\text { 3GPG:GLU17:OE2 }\end{array}$ & 128.230 & 2.31651 & \\
\hline $\begin{array}{l}\text { 3GPG:ARG120:HH21 - } \\
\text { Hesperetin:UNK1:O17 }\end{array}$ & 123.759 & 2.34233 & \\
\hline $\begin{array}{l}\text { 3GPG:LEU108:HN - } \\
\text { Hesperetin:UNK1:O17 }\end{array}$ & 178.542 & 1.72039 & \\
\hline
\end{tabular}




\section{Table 6(on next page)}

Hydrogen bonding between hesperetin and CHIKV nsP4.

This table documents the residues involved in the hydrogen bond formation as well as the angle DHA and length of the hydrogen bonds as analysed using the Discovery Studio 2.5. The binding affinities as ranked by the AutoDock Vina 1.5.6 are recorded in the final column of the table. 


\begin{tabular}{|c|c|c|c|}
\hline Hydrogen bonds & Angle DHA $\left(^{\circ}\right)$ & Distance $(\AA)$ & $\begin{array}{l}\text { Binding Affinity } \\
\text { (kcal/mol) }\end{array}$ \\
\hline $\begin{array}{l}\text { nsP4:GLN364:HE22 - } \\
\text { Hesperetin:UNK1:O21 }\end{array}$ & 148.552 & 2.20397 & \multirow{2}{*}{-7.7} \\
\hline $\begin{array}{l}\text { nsP4:ARG374:HH21 - } \\
\text { Hesperetin:UNK1:O19 }\end{array}$ & 121.976 & 2.4414 & \\
\hline $\begin{array}{c}\text { Hesperetin:UNK1:H3 - } \\
\text { nsP4:ALA104:O }\end{array}$ & 127.732 & 2.19555 & -7.6 \\
\hline $\begin{array}{c}\text { Hesperetin:UNK1:H1 - } \\
\text { nsP4:ALA103:O }\end{array}$ & 147.014 & 1.88423 & -7.5 \\
\hline $\begin{array}{c}\text { nsP4:GLY190:HN - } \\
\text { Hesperetin:UNK1:O20 }\end{array}$ & 123.296 & 2.41584 & \multirow{8}{*}{-7.4} \\
\hline $\begin{array}{c}\text { Hesperetin:UNK1:H2 - } \\
\text { nsP4:ARG110:O }\end{array}$ & 117.610 & 2.16176 & \\
\hline $\begin{array}{c}\text { nsP4:LEU108:HN - } \\
\text { Hesperetin:UNK1:O20 }\end{array}$ & 147.895 & 2.27281 & \\
\hline $\begin{array}{c}\text { nsP4:LEU135:HN - } \\
\text { Hesperetin:UNK1:O17 }\end{array}$ & 126.767 & 2.09964 & \\
\hline $\begin{array}{c}\text { Hesperetin:UNK1:H1 - } \\
\text { nsP4:THR437:O }\end{array}$ & 111.885 & 2.2692 & \\
\hline $\begin{array}{l}\text { Hesperetin:UNK1:H2 - } \\
\text { nsP4:ASP479:OD1 }\end{array}$ & 108.572 & 2.17349 & \\
\hline $\begin{array}{c}\text { nsP4:THR437:HN - } \\
\text { Hesperetin:UNK1:O17 }\end{array}$ & 174.240 & 2.08043 & \\
\hline $\begin{array}{c}\text { nsP4:LEU180:HN - } \\
\text { Hesperetin:UNK1:O19 }\end{array}$ & 117.866 & 2.47914 & \\
\hline
\end{tabular}

1 


\section{Table 7 (on next page)}

Hydrogen bonding between hesperetin and SPK2.

This table documents the residues involved in the hydrogen bond formation as well as the angle DHA and length of the hydrogen bonds as analysed using the Discovery Studio 2.5. The binding affinities as ranked by the AutoDock Vina 1.5.6 are recorded in the final column of the table. 


\begin{tabular}{|c|c|c|c|}
\hline Hydrogen bonds & Angle DHA $\left(^{\circ}\right)$ & Distance $(\AA)$ & $\begin{array}{c}\text { Binding Affinity } \\
\text { (kcal/mol) }\end{array}$ \\
\hline $\begin{array}{l}\text { SPK2:ARG227:HE - } \\
\text { Hesperetin:UNK1:O21 }\end{array}$ & 132.729 & 2.39668 & \multirow{2}{*}{-7.7} \\
\hline $\begin{array}{l}\text { Hesperetin:UNK1:H3 - } \\
\text { SPK2:ALA431:O }\end{array}$ & 106.199 & 2.32194 & \\
\hline $\begin{array}{c}\text { SPK2:GLN223:HE - } \\
\text { Hesperetin:UNK1:O19 }\end{array}$ & 111.042 & 2.45074 & \multirow{5}{*}{-7.6} \\
\hline $\begin{array}{l}\text { SPK2: GLN625:HN - } \\
\text { Hesperetin:UNK1:O17 }\end{array}$ & 110.511 & 2.45589 & \\
\hline $\begin{array}{l}\text { Hesperetin:UNK1:H1 - } \\
\text { SPK2:GLU624:OE1 }\end{array}$ & 139.804 & 2.27908 & \\
\hline $\begin{array}{c}\text { Hesperetin:UNK1:H2 - } \\
\text { SPK2:ARG373:O }\end{array}$ & 129.174 & 1.92199 & \\
\hline $\begin{array}{l}\text { Hesperetin:UNK1:H3 - } \\
\text { SPK2:ASP342:OD1 }\end{array}$ & 141.848 & 2.21488 & \\
\hline $\begin{array}{l}\text { SPK2:ARG227:HE - } \\
\text { Hesperetin:UNK1:O21 }\end{array}$ & 130.540 & 2.3656 & \multirow{3}{*}{-7.5} \\
\hline $\begin{array}{l}\text { Hesperetin:UNK1:H2 - } \\
\text { SPK2:GLN625:O }\end{array}$ & 130.888 & 1.94553 & \\
\hline $\begin{array}{c}\text { Hesperetin:UNK1:H3 - } \\
\text { SPK2:ALA431:O }\end{array}$ & 105.734 & 2.29542 & \\
\hline $\begin{array}{c}\text { SPK2:ASP110:HN - } \\
\text { Hesperetin:UNK1:O17 }\end{array}$ & 152.041 & 2.32426 & \multirow{2}{*}{-7.4} \\
\hline $\begin{array}{l}\text { Hesperetin:UNK1:H1 - } \\
\text { SPK2:CYS100:O }\end{array}$ & 138.862 & 2.43301 & \\
\hline $\begin{array}{c}\text { Hesperetin:UNK1:H2 - } \\
\text { SPK2:ARG373:O }\end{array}$ & 120.303 & 2.05193 & \multirow{2}{*}{-7.3} \\
\hline $\begin{array}{c}\text { Hesperetin:UNK1:H3 - } \\
\text { SPK2:ASP342:OD1 }\end{array}$ & 147.571 & 2.13992 & \\
\hline $\begin{array}{c}\text { SPK2:GLY248:HN - } \\
\text { Hesperetin:UNK1:O19 }\end{array}$ & 134.859 & 2.21696 & \multirow{2}{*}{-7.1} \\
\hline $\begin{array}{l}\text { Hesperetin:UNK1:H1 - } \\
\text { SPK2:CYS276:O }\end{array}$ & 89.142 & 2.41654 & \\
\hline $\begin{array}{l}\text { Hesperetin:UNK1:H1 - } \\
\text { SPK2:THR641:OG1 }\end{array}$ & 135.818 & 2.17768 & -7.0 \\
\hline
\end{tabular}




\section{Table 8(on next page)}

Pi-interactions between hesperetin and respective proteins.

The residues involved and length of each pi-interaction as well as the types of pi-interactions formed were analysed using the Discovery Studio 2.5 . 


\begin{tabular}{|c|c|c|c|}
\hline Protein & Binding & Distance ( $\AA$ ) & Interaction \\
\hline \multirow{6}{*}{ NsP1 } & $\begin{array}{c}\text { Hesperetin:UNK1 - } \\
\text { ARG70:NE }\end{array}$ & 5.2141 & Pi-Cation \\
\hline & $\begin{array}{l}\text { Hesperetin:UNK1 - } \\
\text { nsP1:TYR185 }\end{array}$ & 6.18796 & $\mathrm{Pi}-\mathrm{Pi}$ \\
\hline & $\begin{array}{l}\text { Hesperetin:UNK1 - } \\
\text { nsP1:ARG252:NE }\end{array}$ & 6.85892 & Pi-Cation \\
\hline & $\begin{array}{l}\text { Hesperetin:UNK1 - } \\
\text { ARG252:NE }\end{array}$ & 6.0649 & Pi-Cation \\
\hline & $\begin{array}{l}\text { Hesperetin:UNK1 - } \\
\text { nsP1:PHE43 }\end{array}$ & 6.334 & $\mathrm{Pi}-\mathrm{Pi}$ \\
\hline & $\begin{array}{l}\text { Hesperetin:UNK1 - } \\
\text { nsP1:LYS442:NZ }\end{array}$ & 5.9124 & Pi-Cation \\
\hline \multirow{4}{*}{ 3TRK } & $\begin{array}{c}\text { Hesperetin:UNK1 - } \\
\text { 3TRK:TYR1079 }\end{array}$ & 4.72556 & $\mathrm{Pi}-\mathrm{Pi}$ \\
\hline & $\begin{array}{c}\text { Hesperetin:UNK1 - } \\
\text { 3TRK:TYR1079 }\end{array}$ & 5.65846 & $\mathrm{Pi}-\mathrm{Pi}$ \\
\hline & $\begin{array}{c}\text { Hesperetin:UNK1 - } \\
\text { 3TRK:TYR1177 }\end{array}$ & 4.36635 & $\mathrm{Pi}-\mathrm{Pi}$ \\
\hline & $\begin{array}{l}\text { Hesperetin:UNK1 - } \\
\text { 3TRK:PHE1225:HB2 }\end{array}$ & 2.74925 & Pi-Sigma \\
\hline \multirow{8}{*}{ 3GPG } & $\begin{array}{l}\text { Hesperetin: UNK1 - } \\
\text { 3GPG:TRP148 }\end{array}$ & 5.10212 & Pi-Pi \\
\hline & $\begin{array}{l}\text { Hesperetin: UNK1 - } \\
\text { 3GPG:TRP148 }\end{array}$ & 4.15778 & $\mathrm{Pi}-\mathrm{Pi}$ \\
\hline & $\begin{array}{l}\text { Hesperetin:UNK1 - } \\
\text { 3GPG:LYS118:NZ }\end{array}$ & 3.86706 & Pi-Cation \\
\hline & $\begin{array}{l}\text { Hesperetin:UNK1 - } \\
\text { 3GPG:GLY30:HA1 }\end{array}$ & 2.84749 & Pi-Sigma \\
\hline & $\begin{array}{l}\text { Hesperetin:UNK1 - } \\
\text { 3GPG:VAL113:HB }\end{array}$ & 2.9202 & Pi-Sigma \\
\hline & $\begin{array}{l}\text { Hesperetin:UNK1- } \\
\text { 3GPG:TYR63 }\end{array}$ & 4.02708 & $\mathrm{Pi}-\mathrm{Pi}$ \\
\hline & $\begin{array}{l}\text { 3GPG:TRP148 - } \\
\text { Hesperetin:UNK1 }\end{array}$ & 4.22731 & Pi-Pi \\
\hline & $\begin{array}{c}\text { 3GPG:TRP148 - } \\
\text { Hesperetin:UNK1 }\end{array}$ & 4.05885 & Pi-Pi \\
\hline \multirow{4}{*}{ NsP4 } & $\begin{array}{l}\text { Hesperetin:UNK1 - } \\
\text { nsP4:ARG374:NE }\end{array}$ & 5.53545 & Pi-Cation \\
\hline & $\begin{array}{l}\text { Hesperetin:UNK1 - } \\
\text { nsP4:ARG70:NE }\end{array}$ & 5.3946 & Pi-Cation \\
\hline & $\begin{array}{l}\text { Hesperetin:UNK1 - } \\
\text { nsP4:ARG70:NE }\end{array}$ & 6.64674 & Pi-Cation \\
\hline & $\begin{array}{l}\text { Hesperetin:UNK1 - } \\
\text { nsP4:ARG70:NE }\end{array}$ & 5.65215 & Pi-Cation \\
\hline
\end{tabular}




\begin{tabular}{|c|c|c|c|}
\hline & $\begin{array}{c}\text { Hesperetin:UNK1 - } \\
\text { nsP4:ARG70:NE }\end{array}$ & 5.28131 & Pi-Cation \\
\hline & $\begin{array}{c}\text { Hesperetin:UNK1 - } \\
\text { nsP4:TYR22 }\end{array}$ & 4.15499 & $\mathrm{Pi}-\mathrm{Pi}$ \\
\hline & $\begin{array}{l}\text { Hesperetin:UNK1 - } \\
\text { nsP4:ARG70:NE }\end{array}$ & 4.49028 & Pi-Cation \\
\hline & $\begin{array}{c}\text { Hesperetin:UNK1 - } \\
\text { nsP4:TYR185 }\end{array}$ & 6.16947 & Pi-Pi \\
\hline & $\begin{array}{l}\text { Hesperetin:UNK1 - } \\
\text { nsP4:ARG70:NE }\end{array}$ & 5.20374 & Pi-Cation \\
\hline & $\begin{array}{c}\text { Heesperetin:UNK1 - } \\
\text { nsP4:ARG70:NE }\end{array}$ & 4.51522 & Pi-Cation \\
\hline & $\begin{array}{c}\text { Hesperetin:UNK1 - } \\
\text { nsP4:ARG70:HD1 }\end{array}$ & 2.61933 & Pi-Sigma \\
\hline \multirow{3}{*}{ SPK2 } & $\begin{array}{l}\text { Hesperetin:UNK1 - } \\
\text { SPK2:TYR372 }\end{array}$ & 4.91884 & Pi-Pi \\
\hline & $\begin{array}{l}\text { SPK2:TYR372 - } \\
\text { Hesperetin:UNK1 }\end{array}$ & 4.34443 & Pi-Pi \\
\hline & $\begin{array}{l}\text { Hesperetin:UNK1 - } \\
\text { SPK2:ARG351:NE }\end{array}$ & 6.2923 & Pi-Cation \\
\hline
\end{tabular}




\section{Table 9 (on next page)}

Lipinski's values of the hesperetin molecule designed for this study and that of the available data from PubChem.

A compound with drug-likeness properties should possess molecular weight less than 500

$\mathrm{g} / \mathrm{mol}$, Log $\mathrm{P}$ less than 5 , less than $5 \mathrm{H}$-bond donors, less than $10 \mathrm{H}$-bond acceptors and molar refractivity in the range of 40-130. 


\begin{tabular}{ccc}
\hline Criteria & From the present study & Extracted from PubChem \\
\hline Molecular weight (g/mol) & 302.00 & 302.28 \\
\hline H-bond donors & 3 & 3 \\
\hline H-bond acceptors & 6 & 6 \\
\hline Log-P & 2.5 & 2.4 \\
\hline Molar refractivity & 76.75 & 76.93 \\
\hline
\end{tabular}

1 


\section{Table $\mathbf{1 0}$ (on next page)}

Relative binding free energies of complexes estimated using MM-GBSA.

Note: The EEL and vdW represent the electrostatic and van der Waals contributions from MM, respectively. EGB stands for GB electrostatic contribution to the solvation free energy, and ESURF is the nonpolar contribution to the solvation free energy. $\Delta E_{\text {binding }}$ (in $\mathrm{kcal} \mathrm{mol}^{-1}$, binding energy neglecting the contribution of entropy) is the final estimated binding free energy calculated from the terms above. 
1

\begin{tabular}{cccccc}
\hline Complex & EEL & vdW & EGB & ESURF & $\Delta E_{\text {binding }}$ \\
\hline $\begin{array}{c}\text { 3GPG }+ \\
\text { hesperetin }\end{array}$ & -10.26 & -36.62 & 23.47 & -4.76 & -28.18 \\
\hline $\begin{array}{c}\text { 3TRK }+ \\
\text { hesperetin }\end{array}$ & -4.13 & -28.32 & 18.61 & -3.61 & -17.46 \\
\hline
\end{tabular}

2

3 
Figure 1

The binding positions with the highest binding affinities of hesperetin (yellow ball and stick structure) when docked against different proteins (flat ribbon coloured from N-to-C terminal).

(A) nsP1 with binding affinity of $-7.6 \mathrm{kcal} / \mathrm{mol}$, (B) $3 T R K$ with binding affinity of $-6.9 \mathrm{kcal} / \mathrm{mol}$,

(C) $3 G P G$ with binding affinity of $-8.5 \mathrm{kcal} / \mathrm{mol}$, (D) nsP4 with binding affinity of $-7.7 \mathrm{kcal} / \mathrm{mol}$,

(E) SPK2 with binding affinity of $-7.7 \mathrm{kcal} / \mathrm{mol}$
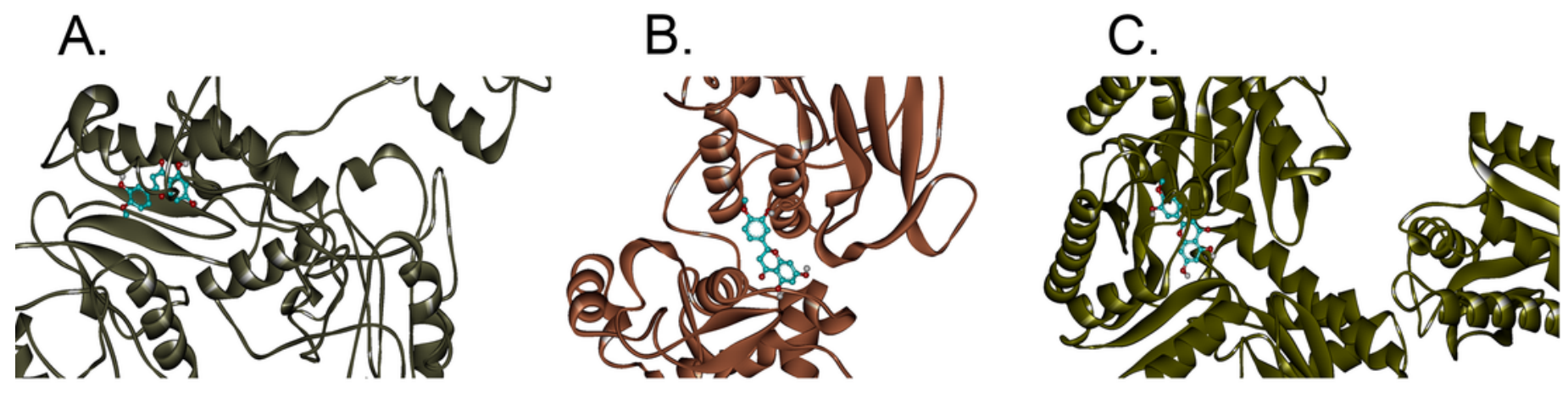

D.

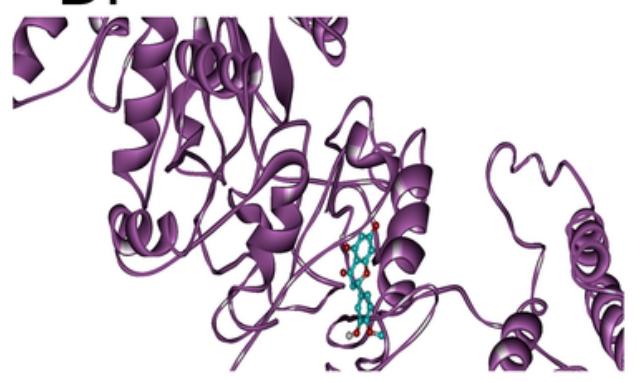

E.




Figure 2

2D diagram of interaction between hesperetin and nsP1.

The diagram shows the ligand-receptor interactions and close amino acid residues found in the binding pocket.

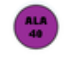

(3)

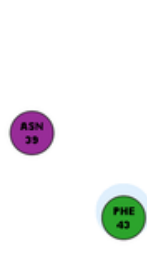

영

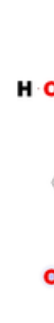

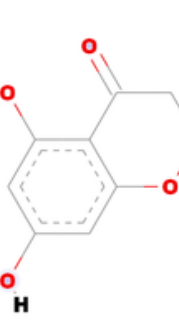

; :



man

(24) 
Figure 3

2D diagram of interaction between hesperetin and 3TRK.

The diagram demonstrates the ligand-receptor interactions and close amino acid residues found in the binding pocket.
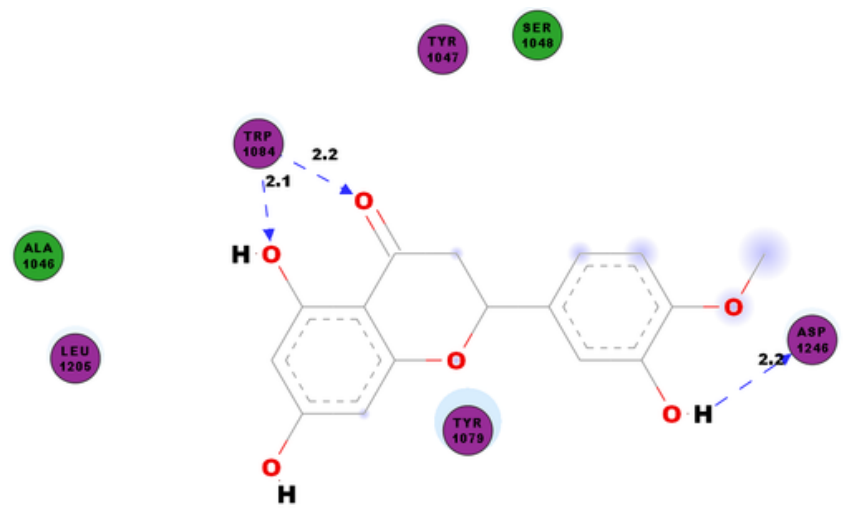

(쇼용

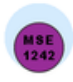


Figure 4

2D diagram of interaction between hesperetin and 3GPG.

The diagram illustrates the ligand-receptor interactions and close amino acid residues found within the binding pocket.

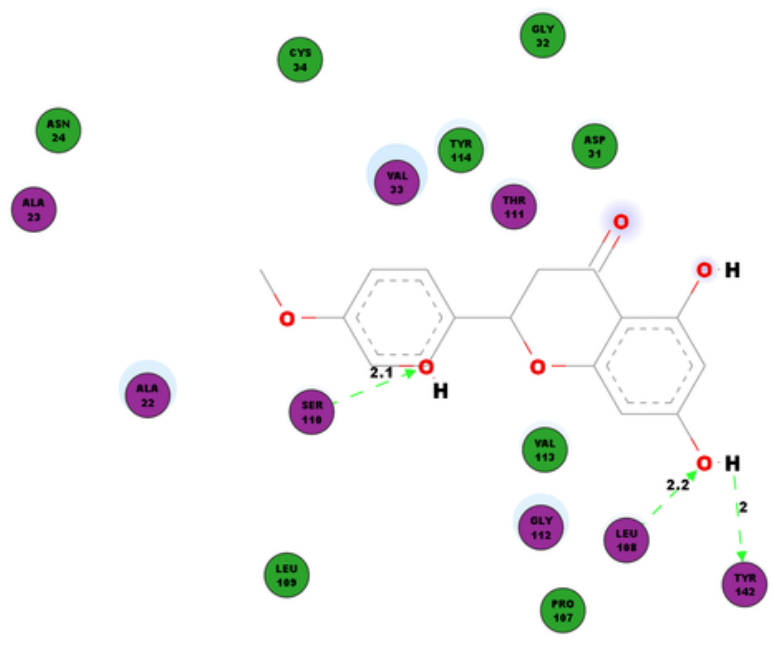

Ast

(ARO)

$\left(\begin{array}{c}63 \\ 143\end{array}\right.$ 
Figure 5

2D diagram of interaction between hesperetin and nsP4.

The diagram shows the ligand-receptor interactions and close amino acid residues found in the binding pocket.




Figure 6

2D diagram of interaction between hesperetin and SPK2.

The diagram demonstrates the ligand-receptor interactions and close amino acid residues found in the binding pocket.

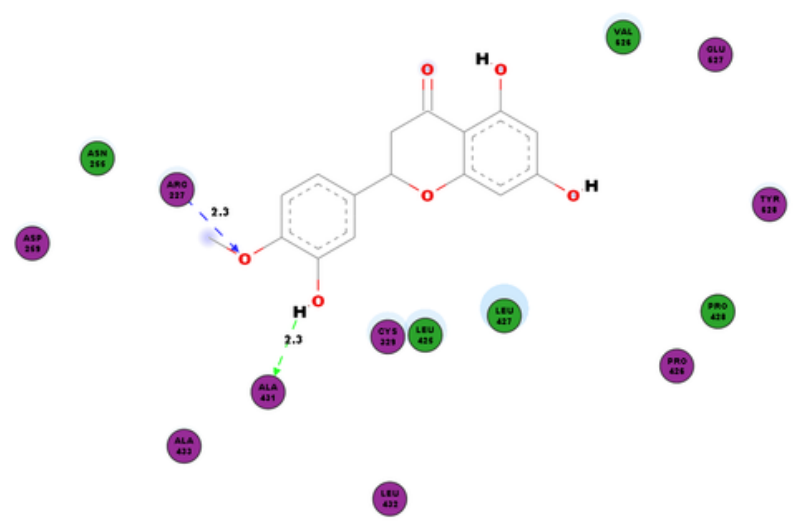




\section{Figure 7}

Time series of RMSD from the minimized starting structure calculated using the backbone atoms of the protein.

RMSD computed with respect to the minimized starting structure is less than $1.8 \AA$, hence showing that the simulated systems are well equilibrated and do not deviate much from the initial starting structure.




Figure 8

Lowest energy structure of ligand-receptor complexes.

A. 3GPG and B. 3TRK in complexed with hesperetin (shown in stick representation, only polar hydrogen is shown). Both complexes remained stable throughout the 10 ns simulations.

A.

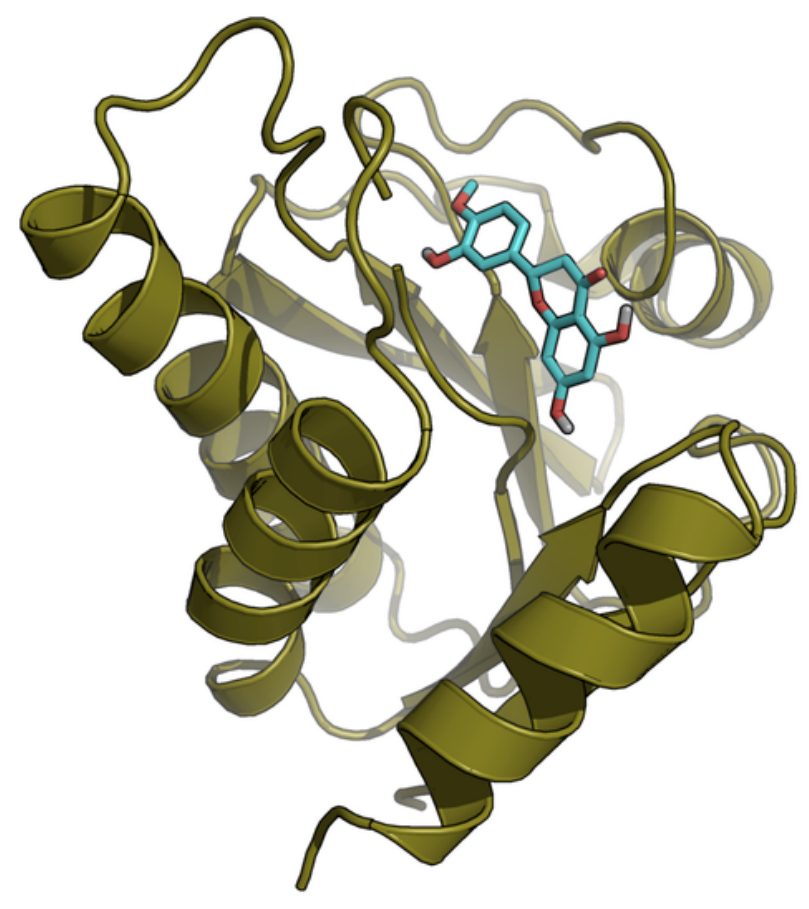

B.

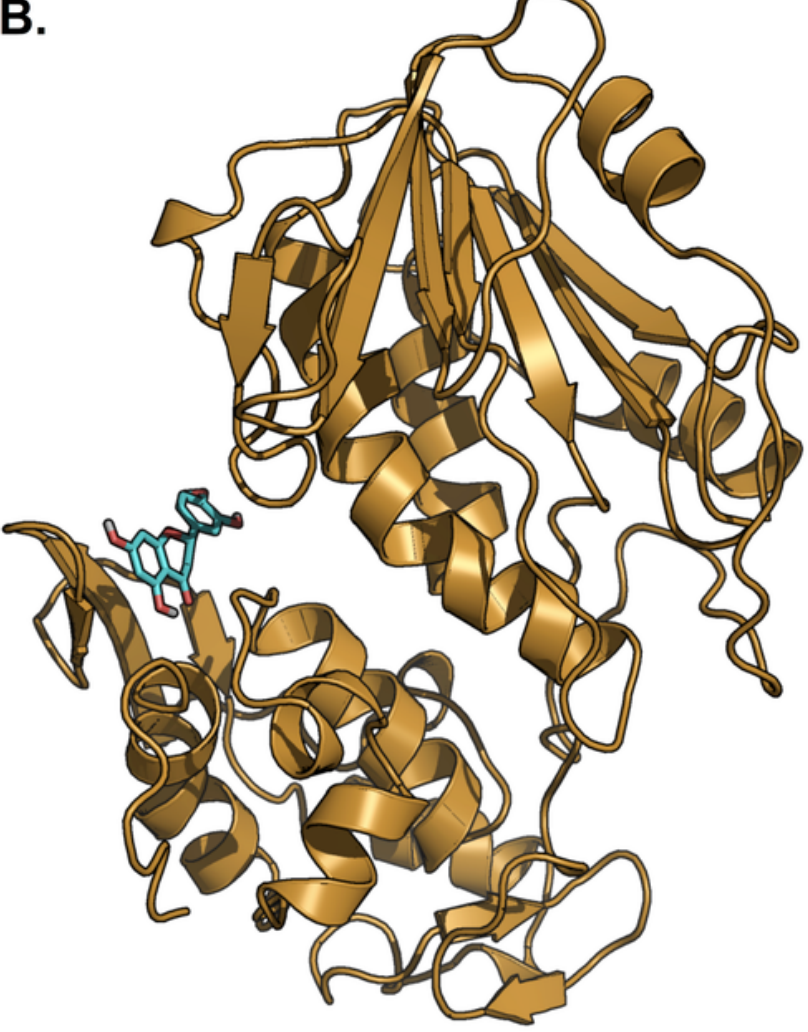

